\title{
A POLÍTICA DE PESQUISA E A IMPLEMENTAÇÃO DO MESTRADO EM CIÊNCIAS FARMACÊUTICAS DA UNIVERSIDADE DE SOROCABA
}

\author{
Marli Gerenutti* \\ Marta Maria Duarte Carvalho Vila** \\ WILSON SANDANO***
}

Recebido em: 19 de agosto de 2009 Aprovado em: 30 de agosto de 2009

\begin{abstract}
*Pró-Reitora de Pós-Graduação e Pesquisa da Universidade de Sorocaba e Professora do Programa de PósGraduação em Ciências Farmacêuticas da Universidade de Sorocaba. E-mail: marli.gerenutti@prof.uniso.br. ***Prof ${ }^{a}$ do Programa de Pós-Graduação em Ciências Farmacêuticas da Universidade de Sorocaba. E-mail: marta.vila@prof.uniso.br.

***Prof. do Programa de Pós-Graduação em Educação da Universidade de Sorocaba. E-mail: wilson. sandano@prof.uniso.br.
\end{abstract}

Resumo: Este artigo objetiva mostrar como uma política de pesquisa, pautada na intervenção para o fortalecimento dos cursos de graduação, pode auxiliar na institucionalização da pesquisa universitária. No caso da Universidade de Sorocaba, a resposta positiva da área de Ciências Farmacêuticas a esta política, associada à Política Nacional de Ciência e Tecnologia e à demanda regional para o desenvolvimento da área de saúde, levou à implementação do Programa de Pós-Graduação stricto sensu em Ciências Farmacêuticas.

Palavras-chave: Pesquisa. Política. Formação. Ciências farmacêuticas.

\section{RESEARCH POLICY AND THE IMPLEMENTATION OF THE PHARMACEUTICAL SCIENCES GRADUATE PROGRAM AT THE UNIVERSITY OF SOROCABA}

Abstract: The purpose of this article is to show how research policies focused on strengthening undergraduate programs can contribute to the institutionalization of university research. In the case of the University of Sorocaba, the positive response from the Pharmaceutical Sciences area to such policy, along with the National Science and Technology Policy and the regional demand for development in the health area, made possible the implementation of the stricto sensu Graduate Program in Pharmaceutical Sciences.

Key words: Research. Policy. Education. Pharmaceutical sciences.

\section{Apresentação}

Na década de 1990, a educação superior no Brasil, como de resto no mundo, foi objeto de profundas transformações, que se estendem até nossos dias. Uma das maiores alterações ocorreu com a concepção de universidade.

Severino nos mostra dois modelos de universidade: um que só privilegiaria a pesquisa; outro que teria como único papel a preparação de técnicos a serviço do mercado de trabalho. Ele nos mostra, também, que a universidade tem sido "pressionada de fora pelas injunções de uma dinâmica social escrava 
do mercado (grifos do Autor), onde só conta o valor de troca, onde tudo de transforma em mercadoria para um consumo desvairado [...].” (SEVERINO, 2009, p. 258)

Foi neste período que surgiu a Universidade de Sorocaba (Uniso) - uma universidade comunitária, oriunda da Faculdade de Filosofia, Ciências e Letras de Sorocaba, criada na década de 1950.

\section{O contexto}

O Estado de São Paulo caracteriza-se como um dos estados de maior desenvolvimento nos mais variados setores. No entanto, há grandes diferenças entre suas regiões, quando se abordam os aspectos de geração de riqueza e inclusão social. A região sul do Estado, que corresponde à antiga Região Administrativa de Sorocaba, é uma das regiões mais pobres do Estado. Embora o Índice de Desenvolvimento Humano (IDH) da Região Administrativa de Sorocaba tenha aumentado com maior rapidez que o IDH estadual, ele sempre esteve em patamar inferior ao seu correspondente estadual. Neste panorama, o município de Sorocaba está próximo das áreas de carência e grande exclusão social do Estado de São Paulo. Este panorama se reflete na escassa formação de recursos humanos qualificados na região. Registre-se que, em relação à educação superior, até o final do século passado, não havia IES pública em Sorocaba ou região.

Assim, de 1988 a 1994, desenvolveu-se o projeto de criação da Universidade de Sorocaba - Uniso, primeira universidade da região. A Comissão Especial Temporária de Universidades, do Conselho Nacional de Educação, através do Parecer CNE/CETU no 488/94, apontou que, no Plano de Expansão do Ensino de Graduação, do Projeto de Universidade da Universidade de Sorocaba, se previa “o início na área de saúde, bastante precária na região”.

Nesta linha, em 1995 foram iniciados os estudos para a implantação e desenvolvimento da Área de Ciências Farmacêuticas na Universidade de Sorocaba, em consonância com sua missão ${ }^{1}$ e a demanda regional.

Em 17 de dezembro de 1996, o Conselho Municipal de Saúde de Sorocaba aprovou, por unanimidade, a criação e instalação da Área de Ciências Farmacêuticas na Universidade de Sorocaba. Em fevereiro de 1997, o Conselho Regional de Farmácia do Estado de São Paulo (CRF-SP) assim se manifestou sobre a necessidade social da criação e implantação da área de Ciências Farmacêuticas na Uniso:

1 Nos termos estatutários, é missão da Uniso: "Ser uma Universidade Comunitária que, por meio da integração de ensino, pesquisa e extensão, produza conhecimentos e forme profissionais, em Sorocaba e Região, para serem agentes de mudanças sociais, à luz de princípios cristãos”. 
A existência de um curso de Farmácia na Região de Sorocaba deverá contribuir muito para o crescimento e aperfeiçoamento dos farmacêuticos que ali atuam, desde que haja uma proposta concreta de intercâmbio com estes profissionais; conseqüentemente poderá ocorrer um avanço quantitativo e qualitativo na relação desses profissionais com a população por eles assistida; a proposta apresenta nitidamente uma preocupação com a formação de um profissional capaz de atuar e intervir nas questões de saúde da população, através de seu conhecimento sobre o medicamento.

Neste contexto, em 1998, a Uniso iniciou o curso de Farmácia, com um corpo docente altamente qualificado científica e academicamente, seguindo sua visão de futuro, ou seja, ser reconhecida pela qualidade do seu ensino, relevância de suas pesquisas e inserção criadora na sociedade.

O impacto da implantação do curso de graduação em Farmácia, no âmbito da Universidade de Sorocaba, proporcionou um repensar acadêmico-científico institucional, pois este curso foi implantado com a premissa de que o ensino de graduação deve ter sua sustentação acadêmica na produção científica institucionalizada e formalizada nos grupos de pesquisa. Neste sentido, a Área de Farmácia foi implantada com foco no desenvolvimento científico, abordando o Serviço Público de Saúde, a Farmácia Hospitalar e a Assistência Farmacêutica. A área da Assistência Farmacêutica, em especial, permitiu a exploração do trabalho científico em linhas de pesquisa previamente existentes no curso, “Uso Racional de Medicamentos” e "Plantas Medicinais”. Vale ressaltar que o curso de Farmácia, por seu aspecto inovador no modelo de integração entre o ensino-pesquisa-extensão, obteve reconhecimento nacional na "II Conferência Nacional de Educação Farmacêutica” (BRASÍLIA, 2001) ao reforçar que “a pesquisa em área básica faz com que o estudante possa optar pela carreira a ser seguida de acordo com suas habilidades e vocação”. Naquele mesmo ano, o curso de Farmácia conquistou o $4^{\circ}$ Prêmio Racine - Construído o Futuro Hoje, com o tema “Qualidade do Ensino Farmacêutico”. O modelo de Projeto Político-Pedagógico do Curso de Farmácia contribuiu para a elaboração das diretrizes atuais da Política de Pesquisa e Pós-Graduação da Uniso.

\section{Pesquisa e pós-graduação para a Uniso}

Em seus quinze anos de existência, a proposta acadêmico-científica da Uniso tem buscado criar condições para alargar e aprofundar a indissociabilidade entre ensino, pesquisa e extensão (Projeto Político Pedagógico - PPI/Uniso). A articulação dessas práticas formativas tem requerido um amplo esforço desta 
Instituição Comunitária em sua missão de formação de agentes para a transformação social. Constitui núcleo temático de suas ações a implementação de uma política de pesquisa e de pós-graduação potencializadora de intervenção na realidade social, em âmbito local, regional e nacional, diante dos desafios representados pela razão de ser da Uniso. (CAMMARANO GONZÁLEZ; GERENUTTI; SANDANO, 2005)

Na universidade, a pesquisa e a pós-graduação são indissociáveis, e a pósgraduação está conceituada como o ambiente para a realização de pesquisa e preparação do pesquisador. A pós-graduação é parte integrante do complexo universitário, necessário à realização de fins essenciais da universidade.

Segundo a LDB (1996), em seu artigo 52 “as universidades constituem-se em instituições pluridisciplinares de formação de quadro de profissionais de nível superior, de pesquisa, de extensão e de domínio e cultivo do saber humano”.

Severino nos lembra que:

[...] Nunca é demais insistir: cabe à universidade como instituição como lugar específico do ensino superior dedicar-se à formação do cidadão autêntico, pois seu papel mais substantivo vai muito além da formação do profissional, do técnico e do especialista. Por mais que os resultados históricos não tenham correspondido a essa expectativa, isso não compromete sua finalidade intrínseca, formadora que precisa ser da consciência social que é a única sustentação de um projeto político minimamente equitativo, justo e emancipador. [...] (SEVERINO, 2009, p. 258)

Essa concepção de universidade nos convida a repensar as formas como efetivamente tem-se organizado a educação superior no Brasil. De acordo com Silva Júnior e Sguissardi (1999) apenas 15\% aproximadamente do alunado do ensino superior do Brasil têm chances de formar-se tendo freqüentado instituições que associariam no âmbito da instituição, atividades de ensino e pesquisa. Estes autores alertam que nem sempre a existência de cursos de pós-graduação é sinônimo de verdadeira pesquisa, havendo uma tendência generalizada nas universidades de separação dos cursos de graduação dos cursos de pós-graduação.

Reconhecemos que, na Uniso, não é muito diferente dessa realidade para algumas áreas, considerando que alguns cursos de graduação têm tido dificuldade de incorporar a pesquisa em suas atividades acadêmicas cotidianas.

Este é nosso desafio:

[...] Só se ganha competência científica se cada curso de graduação conseguir familiarizar os alunos com os fundamentos (epistemes) que sustentam a área científica que informa cada área do conhecimento. 


\begin{abstract}
Este processo requer domínio da evolução histórica da respectiva ciência, domínio dos métodos e linguagens que geraram seus distintos contornos, o diálogo com os “clássicos” respectivos. É na base destes fundamentos que se pode construir o aprender a aprender, condição para o exercício profissional criativo, aquele que não se exaure nos rápidos processos de obsolescência que afetam, hoje, todo exercício profissional. (FORGRAD, 2003, p. 17)
\end{abstract}

Para a Uniso, a pesquisa começa na graduação pelo despertar do espírito investigativo e desenvolve-se na pós-graduação, pela formação de profissionais capazes de produzir conhecimentos e com ele operarem transformações sociais, especialmente nos cursos de pós-graduação stricto sensu.

Entendemos que a pesquisa corresponde a uma atividade de investigação pela qual se constroem explicações consistentes e verossímeis de "fatos do mundo”. Sua característica fundamental é a construção do conhecimento, enquanto representação do real, resultante da aplicação de uma teoria e de um método. A pesquisa não se define por sua base empírica ou pela metodologia aplicada, mas pela formulação da pergunta e das estratégias para respondê-la dentro de um quadro teórico.

É evidente que a possibilidade de pesquisa está atrelada às condições materiais e humanas objetivas da instituição. No caso da Uniso, o tipo de pesquisa mais interessante, mais necessário e que pode trazer maiores benefícios à comunidade é a pesquisa interdisciplinar, regional e aplicada, o que absolutamente não implica o abandono da universalidade (condição de qualquer pesquisa) nem a mera reprodução de modelos já prontos com vista à solução de problemas locais. A pesquisa aplicada só é pesquisa se produzir conhecimento e gerar novos problemas e objetos de investigação. Sua regionalidade só faz sentido se articulada a teorias gerais do conhecimento.

Reconhecendo que a Universidade tem por missão - e, conseqüentemente, obrigação - mostrar e oferecer aos estudantes o caminho para que possam participar ativamente da construção do conhecimento, não podemos compreender a pesquisa como um objeto isolado, inatingível, independente da graduação. A pesquisa alimenta a graduação, instiga o espírito crítico e criativo, devendo ser contemplada em todas as atividades rotineiras do processo pedagógico. Para tanto, a pesquisa deve ser exercida de forma mais estruturada, permitindo que os alunos possam conhecer e optar por propostas novas de trabalho futuro, contribuindo para que o estudante tenha um perfil de inovação e não de subserviência.

É certo que nem todo aluno necessariamente será um pesquisador e que o corpo docente da universidade participa de forma diferenciada da produção 
acadêmico-científica. Porém o exercício da pesquisa contribuirá para que a formação de nosso estudante seja coerente com a missão da Uniso e é inquestionável que, no preparo de aulas, todos docentes devem investir em sua atualização por meio da investigação.

Considerando ainda, que a aprendizagem do método é simultânea à investigação do objeto, o equívoco de tratar as disciplinas de pesquisa como estudo do próprio método, desvinculado da prática investigativa, tem transformado estes momentos em corpos estranhos aos cursos, pouco contribuindo para a inserção dos estudantes de graduação em atividades/projetos de pesquisa. "Disciplinas de pesquisa” não se fazem independentemente dos outros componentes curriculares como se fossem um suporte instrumental. Elas só se justificam se efetivamente se tornarem momentos privilegiados de reflexão e investigação da(s) linha(s) de pesquisa do curso. O docente responsável para levar adiante esta tarefa deve ser pesquisador, estar engajado em práticas investigativas na área de conhecimento do curso, mantendo-se atualizado sobre o que se produz na área. Quanto maior for seu conhecimento do curso, das disciplinas e dos docentes, maiores serão as possibilidades de integração entre as disciplinas de pesquisa e as demais atividades acadêmicas.

\subsection{Política de Pesquisa e Pós-Graduação da Uniso}

Na Uniso até 2004, assuntos envolvendo pesquisa na graduação estavam fragmentados, de um modo geral, em três componentes curriculares, Metodologia do Trabalho Científico (MTC), Métodos e Técnicas de Pesquisa (MTP) e Trabalho de Conclusão de Curso (TCC). A política de pesquisa proposta visou integrar ensino, pesquisa e extensão, possibilitando o tratamento da pesquisa científica de um modo orgânico com a aprendizagem do método se dando simultaneamente a investigação do objeto. Neste sentido, houve a extinção dos componentes curriculares acima citados, que foram substituídos pelo componente curricular "Prática de Pesquisa" a ser desenvolvido nos três últimos períodos do curso, com 02 créditos por período.

Este componente possou a ser de responsabilidade de um grupo de docentes, com perfil ${ }^{2}$ estabelecido pela Pró-Reitoria de Pós-Graduação e Pesquisa e relação de, no máximo, 20 alunos por orientador. Esta inovação permitiu criar condições ao aluno de se formar no ambiente de pesquisa para aplicação na prática profissional

2 Há a exigência de título de doutor ou mestre para a participação no grupo de docentes responsável pela disciplina. 
Vale ressaltar também que, na Política de Pesquisa e de Pós-Graduação da Uniso, as questões relativas ao corpo docente foram as de investimento na formação do professor, objetivando: 1) a formação do docente-pesquisador capaz de captar recursos externos nas agências de fomento à pesquisa; 2) o estabelecimento de políticas de atribuição de carga horária docente relacionada ao professor que desenvolve pesquisa; 3) a valorização, no plano de carreira docente, da produção científica; 4) a definição do perfil e das atribuições do professor em tempo integral envolvido com produção de pesquisa.

Neste contexto, em consonância com o Plano de Carreira Docente da Universidade de Sorocaba ${ }^{3}$, a Política de Pesquisa e Pós-Graduação da Uniso definiu que aos docentes com dedicação de 40 horas semanais dos Programas de Pós-Graduação Stricto Sensu são atribuídas 20 horas semanais para o desenvolvimento de projeto individual de pesquisa e 20 horas para atividades de ensino. São consideradas atividades de ensino, aulas e orientação individual aos alunos. Este regime de dedicação permite ao docente um ambiente propício para exercer suas atividades científicas e contribui para que a Universidade exerça sua atividade fim, ou seja, a produção do conhecimento.

No âmbito da Política de Pesquisa e Pós-Graduação, a Uniso possui indicadores próprios para a avaliação da produtividade docente e discente 4 . Nas questões relacionadas aos alunos de graduação, definiu-se uma política de Iniciação Científica, que gerou um programa de inserção do aluno de graduação em atividades de pesquisa científica, visando interações com o ambiente científico, por meio do desenvolvimento de projeto de pesquisa, de acordo com seu aproveitamento acadêmico e sob a orientação de um professor doutor.

\section{Influências da implantação da política de pesquisa da Uniso na área de Ciências Farmacêuticas}

\subsection{Componente curricular Prática de Pesquisa}

Considerando que as disciplinas de metodologia eram vistas sem grande entusiasmo por uma grande parte dos alunos, este componente curricular foi muito bem avaliado pelos discentes da Uniso e, em particular, do Curso de Farmácia (Figura 01)

3 O Plano de Carreira Docente da Uniso (2006), em seu Capítulo VII - Do Regime de Trabalho, artigo 12, estabelece: que, ao pessoal docente, em regime de 40 horas semanais, serão atribuídas até 20 horas semanais de atividade de Ensino, e as demais horas serão destinadas a pesquisa, extensão e/ou administração universitária. 4 Estes indicadores foram regulamentados pelas Portarias 033/2006 ("Regulamenta a produção acadêmicocientífica de docentes com projetos de pesquisa", 20/11/2006) e 002/2004 ("Regulamenta a produção acadêmico-científica dos discentes matriculados nos Programas de Pós-Graduação Stricto Sensu", 22/11/2004). 


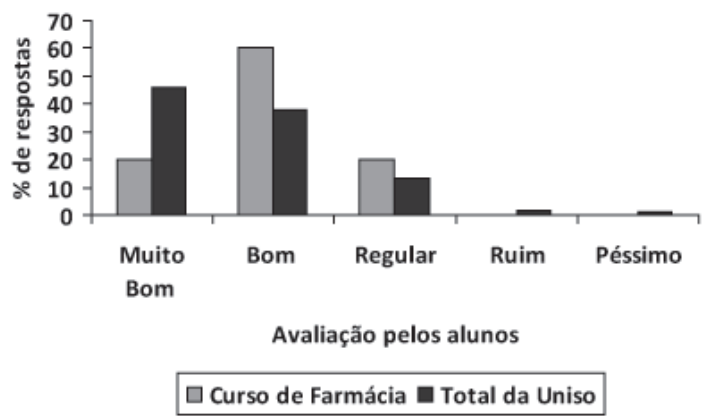

Figura 01: Avaliação do Componente Curricular "Prática de Pesquisa" pelos alunos da Uniso.

Fonte: Pró-Reitoria de Pós-Graduação e Pesquisa - Uniso

\subsection{Programa de Iniciação Científica}

Até o presente momento, foram contemplados 128 alunos para desenvolvimento de projetos de Iniciação Científica do curso de Farmácia (29,69\% do total de projetos de Iniciação Científica institucionais). Atualmente, existem também projetos com bolsas de iniciação financiadas pela Uniso, pela Fundação de Amparo à Pesquisa de São Paulo (FAPESP) e bolsistas do PIBIC-CNPq. A Figura 02 indica o crescente número de alunos do curso de Farmácia que participaram de Programa de Iniciação Científica entre os anos de 2002 a 2008.

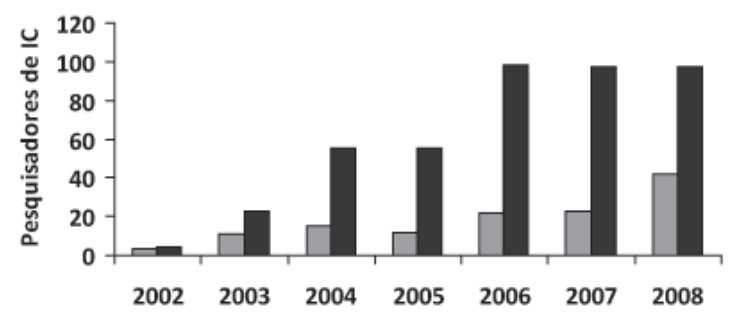

$\square$ Curso de Farmácia $\square$ Total da Uniso

Figura 02: Evolução da participação de alunos de Farmácia no

Programa de Iniciação Científica entre os anos de 2002-2008.

Fonte: Pró-Reitoria de Pós-Graduação e Pesquisa - Uniso 


\subsection{Projetos de Pesquisa com Financiamento Externo}

A partir de 2003, a Pró-Reitoria de Pós-Graduação e Pesquisa, com a finalidade de implementar ainda mais a ambiência de pesquisa da Universidade, abriu diversos Editais para Fomento de Pesquisa. Como resultado destes Editais vários docentes da área de Farmácia foram contemplados com financiamentos de Projetos e horas semanais para dedicação à pesquisa, desenvolvendo atividades de orientação de iniciação científica e projetos (apoiados por agências de fomento e pela Instituição). A Figura 03 mostra a evolução do número de projetos da área de Farmácia aprovados em agências de fomento no período de 2002-2008 comparado ao total da Uniso.

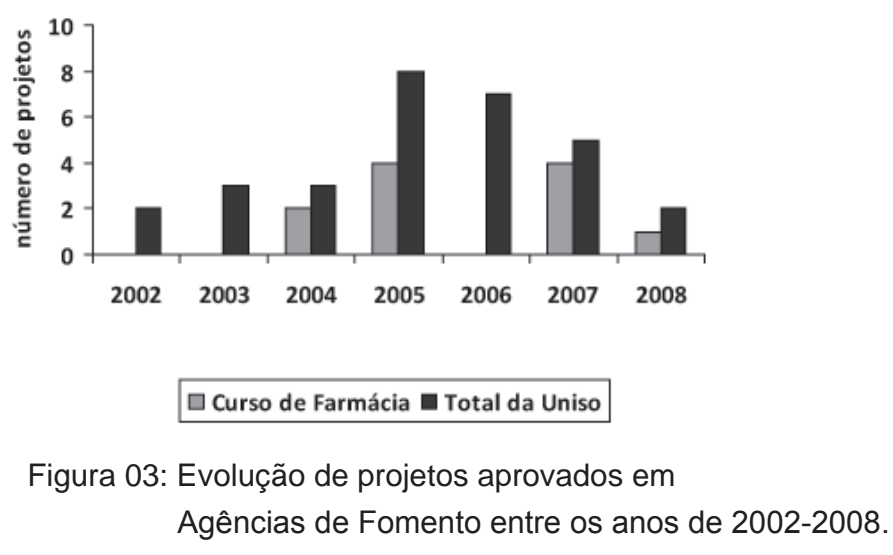

Fonte: Pró-Reitoria de Pós-Graduação e Pesquisa - Uniso

\section{Resultado da política de pesquisa da Uniso na implantação do mestrado em ciências farmacêuticas}

Os resultados elencados no item 4 constituem, no nosso entendimento, um aporte substancial para a implantação do Programa de Pós-Graduação Stricto Sensu, na Área de Ciências Farmacêuticas. Neste sentido, em 16 de fevereiro de 2004, foi aprovado pelo Conselho Universitário o Plano de Desenvolvimento Institucional (PDI 2004-2008), que teve como uma das metas da Política de Pós-Graduação a elaboração da Proposta do Programa de Pós-Graduação Stricto Sensu em Ciências Farmacêuticas.

Além disto, devido a uma expansão da oferta de cursos superiores de graduação nesta região, em especial de cursos diversificados na Área da Saúde e à existência de número reduzido de cursos de mestrado e de doutorado para 
a qualificação de quadro de professores, justifica-se a preocupação da Uniso em suprir esta carência.

Em 28 de março de 2005, o Consu-Uniso aprovou a criação do Programa de Pós-Graduação Stricto Sensu, na área de Farmácia, e enviou à Capes uma Proposta de Mestrado Profissional na Área de Ciências Farmacêuticas, seguindo orientação de sua Diretoria de Avaliação para Universidades Emergentes. Esta Proposta não foi recomendada pela Comissão de Área e a Universidade de Sorocaba enviou em 2007 a Proposta de Mestrado Acadêmico. A implementação do Mestrado em Ciências Farmacêuticas está possibilitando, por meio da formação de pesquisadores qualificados, um acúmulo de produção acadêmicocientífica de contribuição nacional e internacional, reforçando o papel da Uniso como Universidade Comunitária e contribuindo para o crescimento da área de Farmácia no Brasil.

Este curso de Mestrado buscou uma estrutura acadêmica que possibilitasse uma formação humanista, ética, crítica e reflexiva, habilitada a capacitar pesquisadores a absorver e desenvolver, com base no rigor científico, novas tecnologias para atuar em diversos níveis de atenção à saúde. Somando-se a isto, a produção científica docente mostrou-se adequada para atender às exigências da implantação e desenvolvimento deste Programa. Assim, considerou-se que a estrutura da Proposta de Mestrado voltada ao medicamento e saúde, permitiria a disseminação de conhecimento contribuindo para a criação e/ou otimização de processos e produtos farmacêuticos, bem como fornecendo subsídios para o desenvolvimento de uma política de uso racional de medicamentos na Região assistida pela Universidade de Sorocaba. Neste sentido, este curso foi concebido de forma a integrar a inovação tecnológica com a área da saúde, bem como discutir e avaliar políticas, programas e serviços de saúde tendo como Área de Concentração "Medicamentos e Saúde”, contemplando duas Linhas de Pesquisa: "Uso Racional de Medicamentos” e "Desenvolvimento e Avaliação de Substâncias Bioativas”.

A Linha de Pesquisa "Desenvolvimento e Avaliação de Substâncias Bioativas” visa desenvolver projetos que buscam oferecer subsídios para o estudo de novas formulações, sistemas de liberação de fármacos, controle de qualidade de fármacos e medicamentos, estudos de propriedades físico-químicas e microbiológicas, desenvolvimento de métodos analíticos de dosagem e avaliação biológica. A linha de pesquisa “Uso racional de medicamentos” deve contemplar projetos que visam oferecer subsídios para o seu uso apropriado, focados na informação, na pesquisa básica e clínica e no uso adequado de medicamentos pelo Sistema Único de Saúde. 
O percurso formativo é embasado na organização curricular e nas linhas de pesquisas do Programa e direciona a formação do mestre. Este perfil deriva da área de concentração, das linhas de pesquisa e na articulação das disciplinas obrigatórias, complementado pelas disciplinas eletivas. O Programa de Mestrado em Ciências Farmacêuticas busca também, no percurso formativo do aluno, propiciar atuação do corpo docente de maneira integrada, ou seja, promovendo a inter-relação das áreas do conhecimento.

As duas disciplinas obrigatórias “Seminários em Educação e Saúde” e ”Seminários em Projetos: do Desenvolvimento à Avaliação” constituem o campo de conhecimento que orienta os estudos e pesquisas relacionadas às duas linhas de pesquisa do Programa. A disciplina “Seminários em Educação e Saúde” objetiva conduzir o pesquisador ao questionamento crítico sobre temas educacionais da área de saúde e formar profissionais reflexivos sobre as políticas da Educação Superior abordando temas como: avaliação da educação superior, didática, avaliação discente, avaliação institucional, formação do professor, novas tecnologias na educação superior, ética, política de pós-graduação, formação superior em saúde. A disciplina "Seminários em Projetos: do Desenvolvimento à Avaliação” conduz o pesquisador a uma abordagem ética que vai além dos conhecimentos técnicos, mas que permite ao estudante reflexões sobre as políticas desenvolvimento científico-tecnológico da área das Ciências Farmacêuticas. Estas duas disciplinas conferem a este mestrado uma característica particular de formação de profissionais tanto para a docência superior como para a pesquisa científica; as discussões fomentadas pelos assuntos abordados, permitem a compreensão da importância do mestrado acadêmico na formação do educador, independente da área de conhecimento.

\section{Considerações finais}

A Política de Pesquisa e Pós-Graduação da Universidade, desenvolvida de 2002 a 2008, apresentou resultados significativos culminado com o reconhecimento apontado, no recredenciamento da Instituição como Universidade:

[...] a pós-graduação stricto sensu, em fase de implantação, é fundamentada em uma política bem elaborada [...]. Os rápidos avanços no credenciamento dos cursos de pós-graduação refletem esta política. Há diversidade de ações voltadas para a pesquisa, iniciação científica e a extensão, realizadas com competência [...]. ${ }^{5}$

5 Relatório da Comissão de Avaliação Institucional Externa, do Ministério da Educação, datado de 8 de junho de 2009, p. 25. 
O reconhecimento do Mestrado em Ciências Farmacêuticas, pautado na resposta positiva desta área de conhecimento à implantação da Política de Pesquisa e Pós-graduação mostra o caminho adequado escolhido pela Uniso.

O envolvimento do Programa de Mestrado em Ciências Farmacêuticas com a graduação é reforçado com a inserção dos professores nos cursos de graduação, orientação de trabalhos de conclusão de curso e orientação científica. As disciplinas Prática de Pesquisa I, II e III são oferecidas por professores-doutores, tendo sempre a participação de pelo menos um professor do Programa de Mestrado, uma vez que, estas disciplinas foram concebidas de modo a colocar o aluno da graduação em contato direto com a pesquisa alimentando no discente o pensamento científico. A formação de novos pesquisadores, que começa com a Iniciação Científica e a busca da construção do conhecimento, tem relevância na política de Pós-Graduação e Pesquisa na instituição e constitui um compromisso deste Programa. O dever com a formação exige um corpo docente academicamente forte e consciente do significado de suas ações. Os professores do Programa dedicam-se em atividades de graduação e Pós-Graduação, contribuindo de maneira positiva para recíproca integração.

A Uniso tem buscado fortalecer sua pós-graduação Stricto Sensu estabelecendo um ambiente propício às pesquisas e, criando condições de ampliar sua inserção no cenário acadêmico nacional, de forma a contribuir com o Sistema Nacional de Educação e com o Sistema Único de Saúde, pela consolidação do Mestrado em Ciências Farmacêuticas. Neste sentido, os aspectos que devem receber atenção especial nos próximos anos, visando ampliar suas ações na busca por sua consolidação são: ampliação dos projetos de pesquisa submetidos à avaliação por agências de fomento; expansão de ações inovadoras que transcendam as atividades curriculares, tais como seminários internos, grupos de estudos, colóquios e participação em conferências; busca de produção docente homogênea; incentivo à participação dos discentes nas atividades do Programa através grupos de pesquisa e atividades acadêmicas que não se limitem à estrutura curricular e incentivo à produção discente, à participação em eventos da área e publicação de trabalhos em periódicos científicos.

\section{Referências}

BRASIL. Lei no 9.394 de 20 de dezembro de 1996. Estabelece as Diretrizes e Bases da Educação Nacional. Legislação e Normas da pós-graduação Brasileira, Brasília: Funadesp, p. 47-64, 2001. 
BRASIL. Conselho Nacional de Educação. Parecer CNE/CETU nº488/94, aprovado em 07/06/94. Reconhecimento da Universidade de Sorocaba. Documento, Brasília nº 401, p.250-262, jun. 1994.

BRASIL. Ministério da Educação. Instituto Nacional de Estudos e Pesquisas Educacionais. Diretoria de Estatísticas e Avaliação da Educação Superior. Avaliação Institucional. Relatório da Comissão de Avaliação Institucional Externa de 08 de junho de 2009. Brasília, p.1-28. Mimeo.

CAMMARANO GONZÁLEZ, Jorge Luís; GERENUTTI, Marli; SANDANO, Wilson. Política de pesquisa para uma universidade comunitária. Avaliação, Campinas; Sorocaba, v. 10, n. 1, p. 93-104, mar. 2005.

CONSELHO REGIONAL DE FARMÁCIA DO ESTADO DE SÃO PAULO. Ata de Reunião Plenária de 27.01.97. São Paulo, p. 1-11. Mimeo. Ata de Reunião Plenária de 24.02.97. São Paulo, p 1-23. Mimeo. FORGRAD - Fórum de Pró-Reitores de Graduação das Universidades Brasileiras. Documento construído para o I PNG - Proposta de Política para a Graduação. Belo Horizonte, 2003, 31p.

GERENUTTI, Marli. Estágios: implementação de aspectos inovadores. In: CONFERÊNCIA NACIONAL DE EDUCAÇÃO FARMACÊUTICA, 2, 2001. Brasília, DF, p. 64-65.

SEVERINO, Antônio Joaquim. Expansão do ensino superior: contextos, desafios, possibilidades. Avaliação, Campinas; Sorocaba, v. 14, n. 2, p. 253266, jul. 2009.

SILVA JR., João dos Reis; SGUISSARDI, Valdemar. Novas faces da educação superior no Brasil: reforma do Estado e mudança na produção. Bragança Paulista: EDUSF, 1999.

UNIVERSIDADE DE SOROCABA. Estatuto da Universidade de Sorocaba. Disponível em: <http:www.uniso.br/universidade/estatuto.asp>. Acesso em: 23 dez. 2003.

. Regimento da Universidade de Sorocaba. Disponível em:

<http:www.uniso.br/universidade/regimento.asp>. Acesso em: 23 dez. 2003. 
UNIVERSIDADE DE SOROCABA. Plano de Carreira Docente. Sorocaba: Universidade de Sorocaba, 2006.

Plano de Desenvolvimento Institucional da Universidade de Sorocaba - 2004-2008, aprovado pelo Consu em 22 de Março de 2004. Sorocaba, 2004. Mimeo.

Portaria $n^{0}$ 002/2004. Regulamenta a produção acadêmicocientífica dos discentes matriculados nos Programas de Pós-graduação Stricto Sensu. Sorocaba, 2004. Mimeo.

. Portaria $n^{0}$ 033/06. Regulamenta a produção acadêmico-científica de docentes com projetos de pesquisa. Sorocaba, 2006. Mimeo.

UNIVERSIDADE DE SOROCABA. Pró-Reitoria de Pós-graduação e Pesquisa. Para a definição de uma política de pesquisa da UNISO. Sorocaba: Universidade de Sorocaba, 2002. Mimeo.

. Ensinar pela pesquisa: em busca da universidade real. Sorocaba: Universidade de Sorocaba, 2002. Mimeo.

. Fórum de Pesquisa, 1, 2002, Sorocaba. Universidade de Sorocaba, Propg, 2002. Mimeo. . Proposta da PROPG para incorporação da pesquisa pelos cursos por meio de seus projetos pedagógicos e sua visível presença no cotidiano dos cursos. Sorocaba: Universidade de Sorocaba, 2003. Mimeo. 